\title{
Correlation of physicochemical properties and sludge dewaterability under chemical conditioning using inorganic coagulants
}

\author{
Meiqing Niu ${ }^{\mathrm{a}, \mathrm{b}, 1}$, Weijun Zhang ${ }^{\mathrm{a}, *, 1}$, Dongsheng Wang ${ }^{\mathrm{a}, *}$, Yu Chen ${ }^{\mathrm{b}}$, Ronglai Chen ${ }^{\mathrm{b}}$ \\ ${ }^{a}$ Research Center for Eco-Environmental Sciences, Chinese Academy of Sciences, Beijing 100085, China \\ ${ }^{\mathrm{b}}$ Beijing Millions Water Cleaning Agent Co. Ltd., Beijing 100018, China
}

\section{H I G H L I G H T S}

- Waste sludge conditioned with inorganic coagulants.

- Change in physicochemical properties of sludge floc was investigated.

- Chemical conditioning process included rapid aggregation and floc densification.

- SRF correlated well with the change in content of soluble EPS, LB-EPS and TB-EPS.

- Compression of EPS structure was a major mechanism of dewaterability improvement.

\section{A R T I C L E I N F O}

\section{Article history:}

Received 17 April 2013

Received in revised form 27 June 2013

Accepted 29 June 2013

Available online 5 July 2013

\section{Keywords:}

Chemical conditioning

EPS

Inorganic coagulants

Physicochemical properties

Sludge dewaterability

\section{G R A P H I C A L A B S T R A C T}

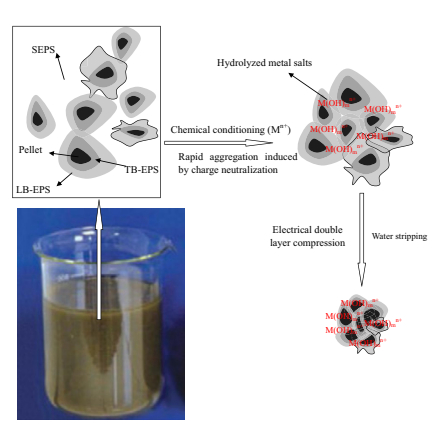

\begin{abstract}
A B S T R A C T
This study investigated the effects of chemical conditioning with three representative inorganic coagulants $\left(\mathrm{FeCl}_{3}\right.$, polyaluminum chloride (PACl) and high performance $\mathrm{PACl}$ (HPAC) on sludge dewaterability. We monitored the particle size, kinetic viscosity $(\mathrm{KV})$, fractal dimension $\left(D_{\mathrm{F}}\right)$ and extracellular polymeric substances (EPS) located in different layers of sludge floc (soluble, loosely-bound (LB), tightly-bound (TB)) to understand the correlation of dewaterability and physicochemical properties of sludge under chemical conditioning. The conditioning process included the rapid aggregation of sludge particles induced by charge neutralization and bridging followed by floc densification caused by double electric layer compression. The floc size and $D_{\mathrm{F}}$ were increased after chemical conditioning, indicating that larger and more compact floc formed. The floc conditioned with $\mathrm{FeCl}_{3}$ was smaller but denser than that of PACl and HPAC. Furthermore, sludge dewaterability correlated well with the change in concentration of soluble EPS, LBEPS and TB-EPS, but not with KV, $D_{\mathrm{F}}$, floc size.
\end{abstract}

(c) 2013 Published by Elsevier Ltd.

\section{Introduction}

Wastewater treatment processes produce large quantities of sludge commonly containing over $90 \%$ water. The management of wastewater sludge accounts for a major portion of the cost of the wastewater treatment process and represents significant technical challenges. In order to reduce the costs of transportation and

\footnotetext{
* Corresponding authors. Tel./fax: +86 1062849138 (W. Zhang).

E-mail addresses: zhwj_1986@126.com (W. Zhang), wgds@rcees.ac.cn (D. Wang).

${ }^{1}$ Co-first authors contributed equally to this work.
}

handling, the most important part of sludge treatment superior to final disposal is the reduction of the sludge volume (Qi et al., 2011). The dewatering process is one of the very expensive and least understood processes in wastewater treatment (Bruus et al., 1992).

It's generally known that the microorganisms are embedded in a matrix of extracellular polymeric substances (EPS). EPS are considered as the key to the physicochemical and biological properties, and are mainly responsible for sustaining the structural and functional integrity of the aggregates. EPS (EPS and water held within the EPS structure) accounts for $80 \%$ of the mass of waste activated sludge, they play important roles in the removal of pollutants from wastewater, bioflocculation, settling and dewatering of 
activated sludge (Simon et al., 2009). It is found that EPS has double layers including the loosely bound EPS (LB-EPS) which is diffused from the tightly bound EPS (TB-EPS) that surrounds the cells (Li and Yang, 2007; Poxon and Darby, 1997; Ramesh et al., 2006), and only the LB-EPS was related to the sludge dewaterability (Li et al., 2012; Li and Yang, 2007; Ramesh et al., 2006). Recently, Yu et al. (2008) suggested that sludge floc was divided into five layers: supernatant, slime, LB-EPS, TB-EPS, and pellet, and the sludge dewatering performance was mainly related to the content and ratio of proteins and polysaccharides of soluble EPS. Therefore, the dewatering performance could be evaluated and predicted by analyzing the organic composition of soluble EPS (Sheng and Yu, 2006).

Chemical conditioning of sludge prior to mechanical dewatering is often necessary to enhance the operating efficiency of dewatering device. Chemical flocculants have been used to improve sludge dewaterability; they can help the sludge particles to flocculate into larger particles or flocs, which are apt to solid-water separation by mechanical methods (Zhai et al., 2012; Zhao, 2002). Inorganic coagulants have been found to act as skeleton builders and reduce the solids compressibility. Therefore, it is especially beneficial when a high pressure dewatering method, such as using a filter press, is adopted, as high porosity of the solids cake needs to be maintained under high pressure (Dentel et al., 2000; Qi et al., 2011).The most commonly inorganic coagulants in water and wastewater treatment are aluminum salts and iron salts. PACl has many advantages over conventional coagulants including less sludge production, insensitive on change of temperature and $\mathrm{pH}$ and high charge neutralization property (Matsui et al., 2003). Inorganic polymer flocculants (such as $\mathrm{PACl}$ its composite coagulantHPAC) contain a range of pre-formed $\mathrm{Al}(\mathrm{III})$ hydrolysis species with high charge density and possess structure, which are fairly stable to further hydrolysis, resulting in higher coagulation efficiency (Wu et al., 2008). Ferric ions are also important for maintaining the floc structure because they can form bonds with exopolymers in the sludge matrix, probably by binding to carboxyl and hydroxyl groups (Steiner et al., 1976). Additionally, Wen et al. (1997) reported that the $D_{\mathrm{F}}$ of the sludge floc was sensitive to dose of chemical conditioners. Yet it seems that there is no sufficient data in the previous literatures to identify the complex change of floc properties to the addition of inorganic chemical conditioner.

The objectives of the present study was to (1) investigate the influence of chemical conditioning with inorganic coagulants on sludge dewatering performance; (2) understand the change in physical (particle size, KV, $D_{\mathrm{F}}$ ) and chemical (EPS composition) properties of sludge flocs under conditioning; (3) get insights into the correlations between sludge dewaterability and the physicochemical characteristics of sludge system; (4) propose a model of floc change in response to chemical conditioning.

\section{Methods}

\subsection{Waste sludge}

Sewage sludge was obtained from Northern brook wastewater treatment plant. It treats approximately $100,000 \mathrm{~m}^{3}$ of wastewater daily, $40 \%$ of total flow is treated by Anaerobic-Anoxic-Oxic (A/A/O) and other $60 \%$ is reused after treatment by Membrane Bio-Reactor (MBR). Sample was stored at $4{ }^{\circ} \mathrm{C}$ and was analyzed within 7 days after sampling. The characteristics of the sludge are listed in Table 1.

\subsection{Chemical agents}

Three coagulants, PACl, a composite coagulant (HPAC) and ferric chloride, were used in this study. Coagulants were liquid and
Table 1

Characteristics of waste sludge.

\begin{tabular}{lllll}
\hline Indicator & Solid $(\%)$ & $\mathrm{pH}$ & TOC $(\mathrm{mg} / \mathrm{g}$ dry solid $)$ & SRF $\left(10^{10} \times \mathrm{m} / \mathrm{kg}\right)$ \\
\hline Value & 1.21 & $6.48-7.12$ & 4.995 & 172 \\
\hline
\end{tabular}

produced by a local factory (Beijing Millions Water Cleaning Agent Co., China). The $\mathrm{Al}_{2} \mathrm{O}_{3}$ content of $\mathrm{PACl}$ and $\mathrm{HPAC}$ is $10 \%$, and the mass concentration of $\mathrm{FeC}_{3}$ is $38 \%$. HPAC is made from $\mathrm{PACl}$ with organic additives during the polymerization process. Basic information of coagulants was given in Table 2 .

\subsection{Sludge conditioning}

The sludge was mixed with a conventional jar-stirring device. Sludge samples of $500 \mathrm{~mL}$ in $1000 \mathrm{~mL}$ beakers were used in the experiments. The following mixing procedure was used: a rapid mix period for $30 \mathrm{~s}$ at $200 \mathrm{rpm}$ followed by a slow-stir phase at $50 \mathrm{rpm}$ for $10 \mathrm{~min}$. The coagulants (\%, g/g dry solid (DS)) were added under agitation using a graduated finnpipette. At the end of mixing, the conditioned sludge was allowed to settle in the beaker for $30 \mathrm{~min}$. Finally, the KV and MW of supernatant were measured.

\subsection{Determination of sludge dewaterability}

Since the determination of specific resistance to filtration (SRF) has the similar physical process to the high pressure dewatering, it was used to evaluate the sludge dewaterability in this work. The SRF was conducted in a $250 \mathrm{~mL}$ Buchner funnel using a filter with $0.45 \mu \mathrm{m}$ filter paper. The Buchner funnel was filled with $100 \mathrm{~mL}$ of the sludge suspension, and a constant pressure of 0.6 MPa was applied by an air pump. The volume of filtrate under pressure was continuously recorded every $10 \mathrm{~s}$ before surface cracking was detected. The SRF of the sludge was calculated by:

$r=\frac{2 P A^{2} b}{\mu \omega}$

where $P\left(\mathrm{~kg} / \mathrm{m}^{2}\right)$ is the pressure applied, $A\left(\mathrm{~m}^{2}\right)$ is the filter area, $\mu$ $\left(\mathrm{kg} \mathrm{s} / \mathrm{m}^{2}\right)$ is the $\mathrm{KV}, \omega\left(\mathrm{kg} / \mathrm{m}^{3}\right)$ denotes dry solid weight per unit volume sludge on the filtrate media, $b$ is the time -to-filtration ratio, which is the slope of the curve that is obtained by plotting the ratio of the time of filtration to the volume of filtrate $(t / V)$ versus the filtrate volume $(V)$.

\subsection{EPS extraction and analysis}

A heat extraction method was modified to extract the LB-EPS and TB-EPS from the sludge (Liyun Ge and Ma, 2006). A sludge suspension was firstly dewatered by centrifugation in a $50 \mathrm{~mL}$ tube at $3000 \mathrm{~g}$ for $10 \mathrm{~min}$. The supernatant was collected as soluble EPS to analyze the TOC and MW composition. The sludge pellet in the tube was then resuspended into $15 \mathrm{~mL}$ of $0.05 \% \mathrm{NaCl}$, sonicated at $20 \mathrm{kHz}$ for $2 \mathrm{~min}$, shaken horizontally at $150 \mathrm{rpm}$ for $10 \mathrm{~min}$, sonicated again for an additional $2 \mathrm{~min}$. The liquor was centrifuged at $8000 \mathrm{~g}$ for $10 \mathrm{~min}$ to separate solids and supernatant. The collected supernatant was regarded as the LB-EPS. The residual sludge pellet left in the centrifuge tube was resuspended in a $0.05 \% \mathrm{NaCl}$ solution, sonicated for $3 \mathrm{~min}$, then heated at $80^{\circ} \mathrm{C}$ for $30 \mathrm{~min}$, finally centrifuged at $12,000 \mathrm{~g}$ for $20 \mathrm{~min}$ to collect TB-EPS. The organic content of LB-EPS and TB-EPS were measured with Total Organic Carbon (TOC) analyzer (Liyun Ge and Ma, 2006).

\subsection{High performance size-exclusion chromatography analysis}

High performance size-exclusion chromatography (HPSEC) was used to measure the molecule weight (MW) distribution (Wang 
Table 2

Properties of inorganic coagulants.

\begin{tabular}{|c|c|c|c|c|c|c|c|c|c|}
\hline & \multicolumn{3}{|c|}{ Results of ferron test (\%) } & \multirow[t]{2}{*}{$\mathrm{pH}$} & \multirow[t]{2}{*}{ Insoluables (\%) } & \multirow[t]{2}{*}{ Basicity (\%) } & \multirow[t]{2}{*}{ Free acid $(\mathrm{mg} / \mathrm{L})$} & \multirow[t]{2}{*}{$\rho(\mathrm{g} / \mathrm{ml})$} & \multirow[t]{2}{*}{ Zeta potential $(\mathrm{mV})$} \\
\hline & $\mathrm{Al}_{\mathrm{a}}$ & $\mathrm{Al}_{\mathrm{b}}$ & $\mathrm{Al}_{\mathrm{c}}$ & & & & & & \\
\hline $\mathrm{PACl}$ & 31.3 & 16.1 & 52.6 & 4.15 & 0.112 & 55.53 & - & 1.2268 & 43.1 \\
\hline HPAC & 19.8 & 26.8 & 53.4 & 4.43 & 0.089 & 62.14 & - & 1.2230 & 58.6 \\
\hline $\mathrm{FeCl}_{3}$ & - & - & - & 3.8 & - & - & 0.1 & 1.4200 & - \\
\hline
\end{tabular}

et al., 2010). MW was measured by a Waters liquid chromatography system which was consisted of Waters 2487 Dual $\lambda$ Absorbance Detector, Waters 1525 pump system. A Shodex KW 802.5 column (Shoko, Japan) was used for separation. The mobile phase, Milli Q water buffered with $5 \mathrm{mM}$ phosphate to $\mathrm{pH} 6.8$, and $0.01 \mathrm{M}$ $\mathrm{NaCl}$, was filtered through a $0.22 \mu \mathrm{m}$ membrane, and then degassed for $30 \mathrm{~min}$ by means of ultrasonication for $0.5 \mathrm{~h}$ before being used to the column. $600 \mu \mathrm{L}$ Sample was injected at a flow rate of $0.8 \mathrm{ml} \mathrm{min}{ }^{-1}$. Polystyrene sulfonate standards (Sigma-Aldrich, USA) of molecular weights 1.8-32 kDa were used for apparent molecular weight (AMW) calibration.

\subsection{Floc morphology}

A laser diffraction instrument (Malvern Mastersizer 2000, Malvern, UK) was used to measure dynamic floc size and structure. Mandelbrot deduced that the compass dimension in 1982, which is available for the measurement of the $D_{\mathrm{F}}$ with rough curve (Mandelbrot, 1982). The compass dimension is the length of rough curve which can be measured by yardstick at different scales. It is shown that yardstick scale $\varepsilon$ dependence for times of yardstick measurement $N(\varepsilon)$, in particular the general trend showing a decrease in yardstick scale increases, in the form of:

$N(\varepsilon) \propto \varepsilon^{D}$

where $D$ is called the compass dimension of rough curve, accordingly the length of curve and $\varepsilon$ can be expressed as follows:

$L=N(\varepsilon) \varepsilon \propto \varepsilon^{1-D}$

it was found that $D_{\mathrm{F}}$ would be indicated by the compass dimension plus 1 .

\subsection{Other analytic methods}

KV was determined using a DV-III viscosity meter. TOC was determined with a TOC analyzer (TOC-VCPH, SHIMADZU, Japan).

\subsection{Statistical analysis}

Correlation analysis was carried out using the software SPSS version 19.0 for Windows (SPSS). Pearson's correlation coefficient $(R)$ was used to evaluate the linear correlation between physicochemical indicators and SRF. Pearson's coefficient can range between -1 and +1 , where -1 denotes a perfect negative correlation, +1 denotes a perfect positive correlation, and 0 denotes the absence of a relationship. The correlations were considered statistically significant at a 95\% confidence interval $(p<0.05)$.

\section{Results and discussion}

\subsection{Effect of chemical conditioning on sludge dewatering}

The SRF of raw sludge was $1.72 \times 10^{10} \mathrm{~m} \mathrm{~kg}^{-1}$. As depicted in Fig. 1, the dosage ranged from $5 \%$ to $10 \%$ (g/g DS), the SRF declined from $126 \times 10^{10} \mathrm{~m} \mathrm{~kg}^{-1}$ to $55.4 \times 10^{10} \mathrm{~m} \mathrm{~kg}^{-1}$ for $\mathrm{PACl}$, from $39.8 \times 10^{10} \mathrm{~m} \mathrm{~kg}^{-1}$ to $15.5 \times 10^{10} \mathrm{~m} \mathrm{~kg}^{-1}$ for HPAC. The sludge dewaterability did not improve significantly with further increase in the PACl and HPAC dosages. The optimal dosage was 5-10\% ( $\mathrm{g} / \mathrm{g}$ DS) and the SRF was $18 \times 10^{10}-6.82 \times 10^{10} \mathrm{~m} \mathrm{~kg}^{-1}$ when the sludge was conditioned with $\mathrm{FeCl}_{3}$. In addition, overdose was found to occur when the total dosage exceeded $10 \%$ (g/g DS), and $\mathrm{FeCl}_{3}$ was relatively more effective than the PACl and HPAC.

\subsection{Influence of chemical conditioning on physical-chemical characteristics of waste sludge}

\subsubsection{Physical properties}

3.2.1.1. Floc size and $D_{F}$. A comparison of floc formation process of sludge conditioning with different inorganic coagulants was monitored by using Mastersizer 2000. Floc size sharply increased to the maximum value once the coagulants were added into the sludge system, and then it decreased with increasing dosage (see in Fig. S1 of Supporting information (SI)). It revealed that sludge condition with inorganic coagulants might be divided into two steps. Initially, sludge particles rapidly aggregated into large flocs due to bridging and charge neutralization, hydrolysis products of inorganic coagulants could neutralize the surface charge of the particles and the suspension would be destabilized (Higgins and Novak, 1997). And then the floc size decreased gradually owing to water stripping from aggregates caused by double electric layer compression as reaction time was going on. Finally, when the balance between the rate of aggregation and the rate of breakage for a given shear condition was reached, the size of flocs reached a steady plateau (Biggs et al., 2001).

In addition, sludge conditioning with iron and aluminum salts showed the different influence on floc size (see Fig. 2a). Firstly, the size of sludge particles conditioned with PACl and HPAC were much larger than that of $\mathrm{FeCl}_{3}$. This was because that the polynuclear species $\left(\mathrm{Al}_{\mathrm{b}}\right.$ and $\left.\mathrm{Al}_{\mathrm{c}}\right)$ accounted for $60-80 \%$ of total $\mathrm{Al}$, while the hydrolytic products of $\mathrm{Fe}^{3+}$ existed in the form of iron

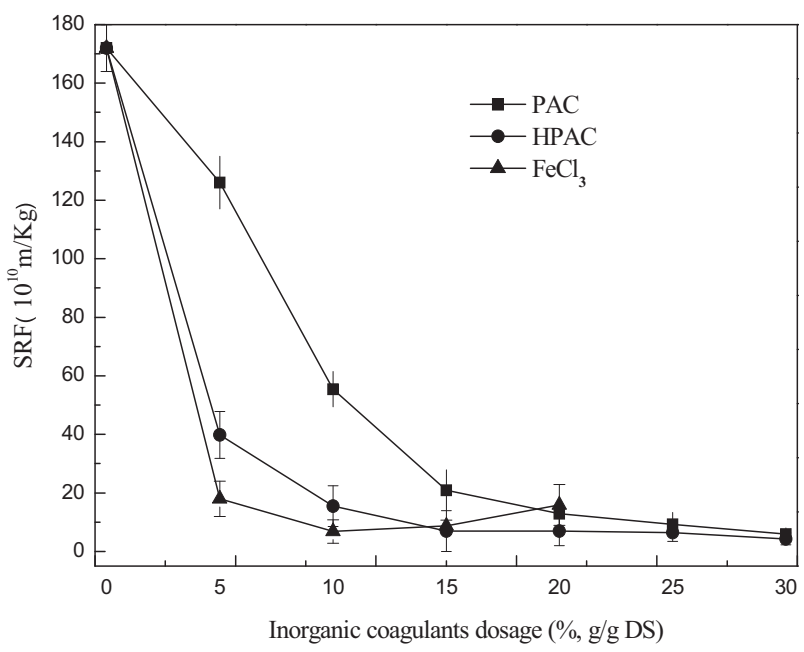

Fig. 1. Effect of chemical conditioning with different coagulants on SRF of waste sludge. 

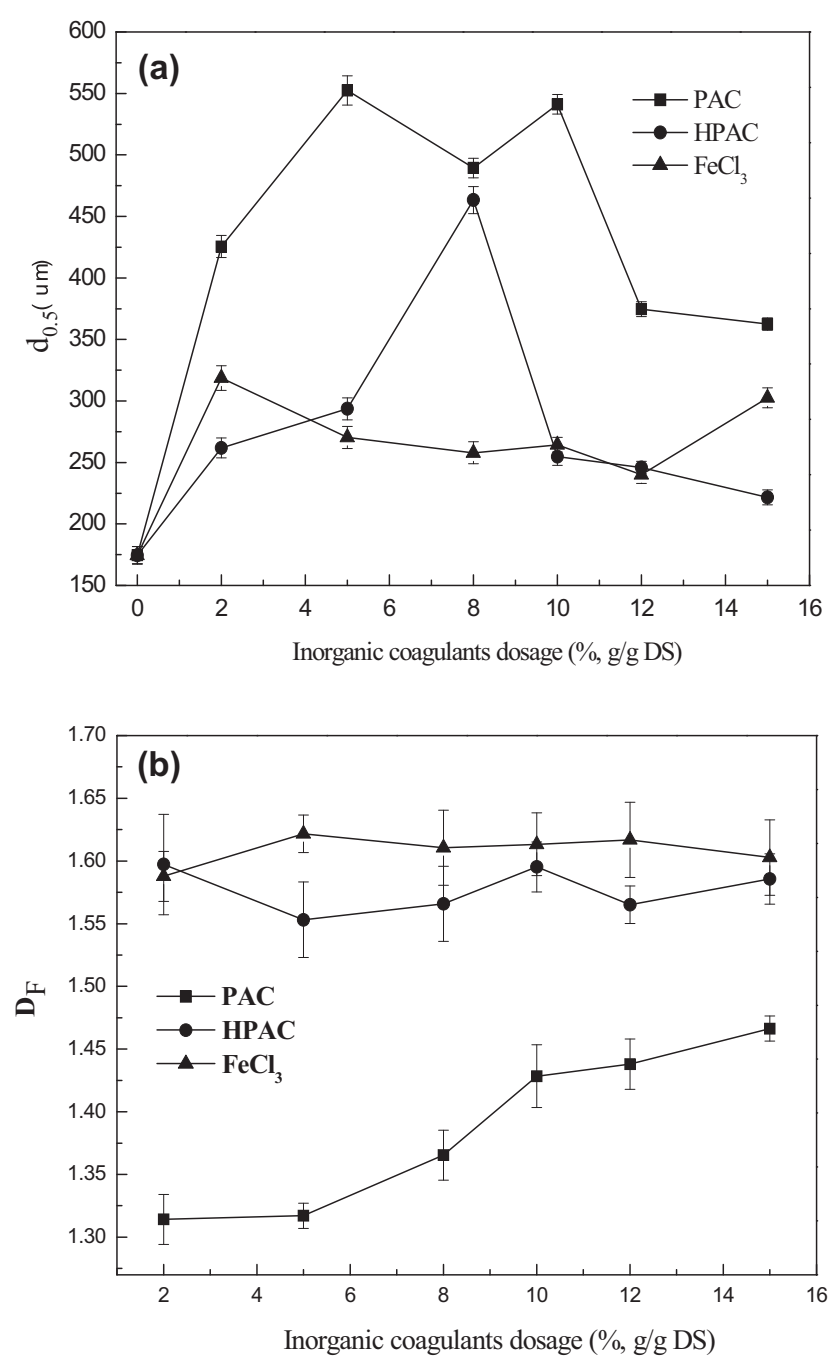

Fig. 2. Influence of inorganic coagulants dosage on sludge floc size (a) and $D_{\mathrm{F}}(\mathrm{b})$.

hydroxides. Therefore, the binding sites of $\mathrm{PACl}$ are much abundant than that of iron hydroxides, thus producing the larger flocs. Secondly, the floc size rose firstly and went down with continual increasing in dosage of $\mathrm{PACl}$ and HPAC, while the floc size increased initially and remained stable for $\mathrm{FeCl}_{3}$ conditioning. This observation might be attributed to difference in charge density of inorganic coagulants. The charge density of PACl and HPAC was much higher than that of $\mathrm{FeCl}_{3}$. At low dosages, sludge particles aggregated due to charge neutralization. However, the charge reversal in sludge system occurred when the dosage of $\mathrm{PACl}$ and HPAC was more than $8 \%$ and $10 \%$ (g/g DS) (see in Fig. S2 of SI). As a result, the colloidal particles re-stabilized again and then rapid decrease in floc size was detected. It is worthy to note that since the charge density of HPAC was higher than PACl, this observation was more apparent for HPAC.

The compass dimension was calculated using step method of the software New scan. Compass dimension of $5 \% \mathrm{FeCl}_{3}$ (g/g DS) for example can be seen in Fig. S3 of SI. $\lg L$ showed a linear relationship with $\lg \varepsilon$ in different step interval. Isotropy appeared to the outer of sludge, it was found that surface $D_{\mathrm{F}}$ would be indicated by the compass dimension plus 1 . Generally, the higher the dimension is the more irregular the surface of the sludge is. Generally, a floc with a $D_{\mathrm{F}}$ close to 3 indicates a close interior packing, and an extremely loose packing feature appears at a $D_{\mathrm{F}}$ close to 1 (Hung et al., 1996).

As depicted in Fig. 2b, $D_{\mathrm{F}}$ of floc increased from 1.42 to 1.6 and 1.57 when the sludge was conditioned with $\mathrm{HPAC}$ and $\mathrm{FeCl}_{3}$ at the

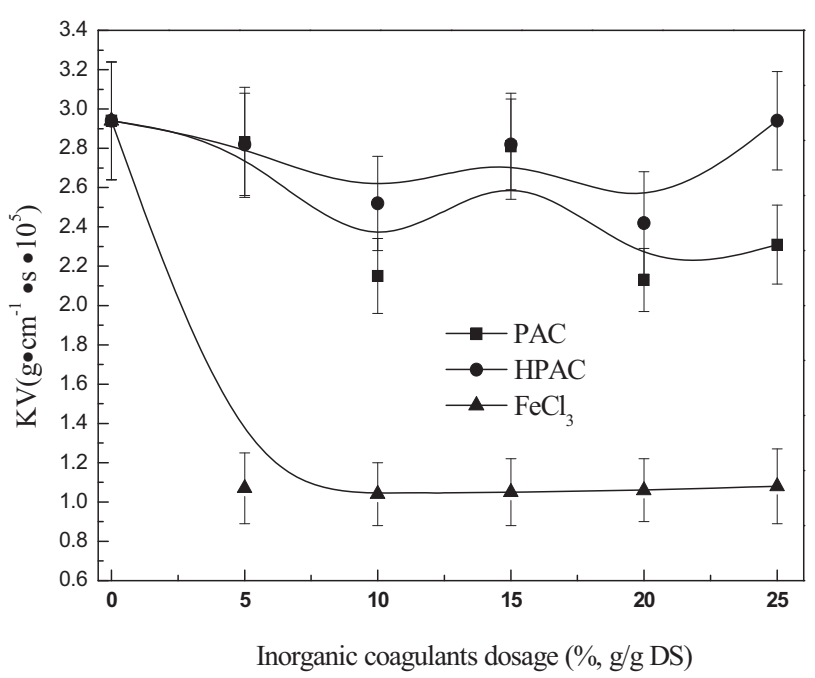

Fig. 3. Influence of chemical conditioning with different inorganic coagulants on KV of sludge.

dosage of $2 \%$ (g/g DS), and it remained stable with further increase in dosage of two coagulants. Higher charge-density coagulants interact strongly with negatively charged surfaces, and will thus have a flat adsorption conformation. Therefore, the flocculated particles will come in close contact with each other, which gives a strong binding and reduces the possibility of movement of the particles relative each other (Eriksson and Alm, 1993). However, PACl conditioning led to reduction in $D_{\mathrm{F}}$ of sludge floc at low dosages, while it increased with increasing dosages of PACl. Since HPAC carried higher charge density of $\mathrm{PACl}$, the binding capacity of HPAC with sludge particles was stronger than $\mathrm{PACl}$, producing the more compact floc. The sludge floc conditioned with $\mathrm{FeCl}_{3}$ was small and regular, which was reflected in higher $D_{\mathrm{F}}$ value. Additionally, the $D_{\mathrm{F}}$ of conditioned sludge flocs increased gradually with reaction time (see in Fig. S4 in SI). This observation revealed that sludge flocs became more and more compact at the stage of compressing double electric layers. There is no consistent tread in $D_{\mathrm{F}}$ when the sludge was affected by different coagulants conditioning in the current study. However, it is noted that sludge samples conditioned with $\mathrm{FeCl}_{3}$ showed the highest $D_{\mathrm{F}}$, indicating that flocs produced from $\mathrm{FeCl}_{3}$ conditioning were smaller but more rigid than that from $\mathrm{PACl}$ and HPAC conditioning.

3.2.1.2. KV of sludge supernatant. The KV is a reflection of the magnitude of particles interaction in a suspension (Dentel et al., 2000). The measurement and assessment of KV in aqueous phase of sludge is simple and could be applied on-line (Slatter, 1997), and a poor dewaterability was always related to increasing KV (Christensen et al., 1993).

The results shown in Fig. 3 indicated that KV sharply decreased with increasing $\mathrm{FeCl}_{3}$ dosage, and then kept balance at higher dosages. As for the sludge conditioned with PACl and HPAC, the KV decreased firstly and went up as the dosage increasing. It was probably that the positively charged and site-bound metal hydrolysis products may neutralize the surface charge of the sludge particles at the dosage of less than $10 \%$ (g/g DS), while the suspension was destabilized as the dosage increasing further, thus leading to increasing in KV. As mentioned above, the hydrolysis products of $\mathrm{FeCl}_{3}$ were mainly in the form of iron hydroxide, and the removal of soluble EPS by coagulation contributed to decrease in KV. Apparently, the KV cannot be used to predict or evaluate the effects of chemical conditioning with inorganic coagulants. 


\subsubsection{Chemical properties}

3.2.2.1. Effect of chemical conditioning on EPS located in different layers of sludge floc. It was widely reported that the EPS impacted the sludge dewaterability (Jin et al., 2004; Mikkelsen and Keiding,
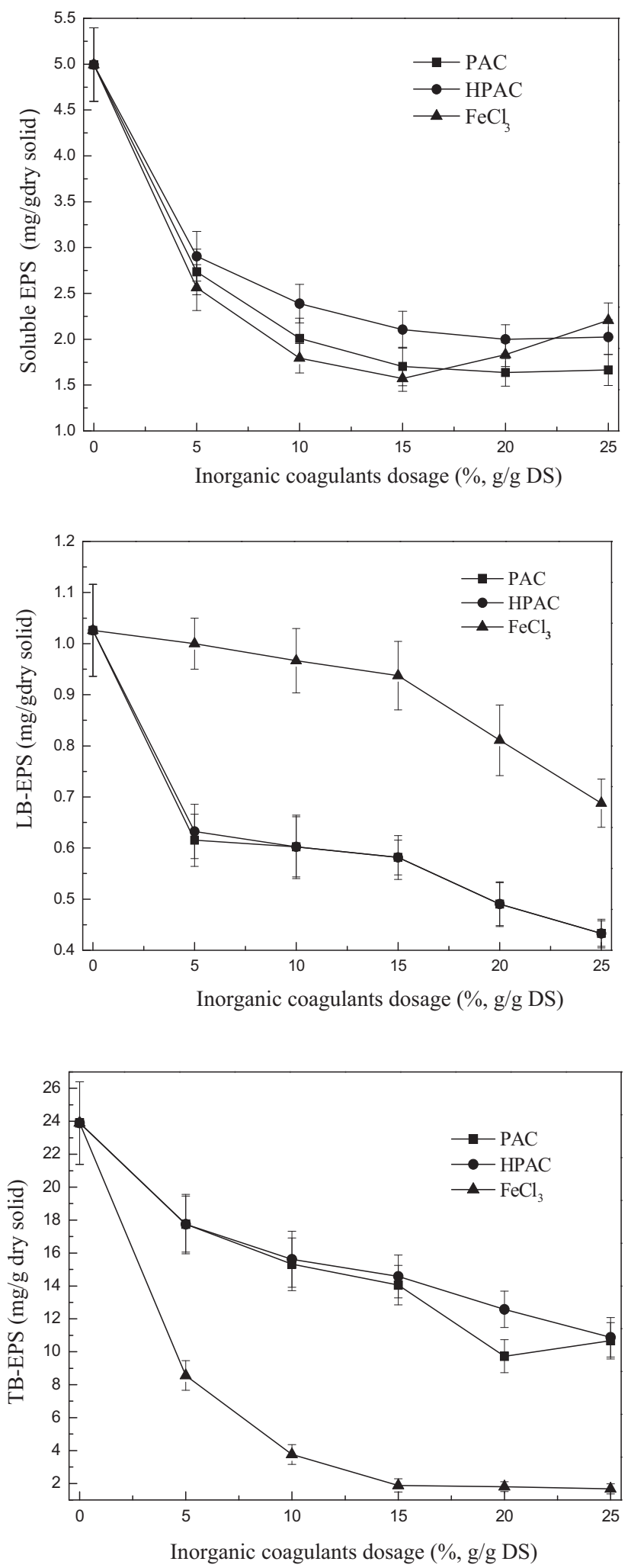

Fig. 4. Effect of chemical conditioning on content of biopolymers located in different sludge layers
2002; Yang and Li, 2009; Poxon and Darby, 1997), but the precise role of EPS on dewaterability usually appeared ambiguous.

As shown in Fig. 4, the EPS contents in the supernatant, LB-EPS, TB-EPS accounted for about $16.5 \%, 3.9 \%$, and $79.5 \%$ of the total EPS concentration in sludge respectively. The concentration of extractable EPS (soluble EPS, LB-EPS and TB-EPS) reduced when the sludge was treated with inorganic coagulants at low dosages. This result indicated that both LB-EPS and TB-EPS were compressed, which led to the sludge flocs becoming more compact upon the addition of inorganic coagulants. Therefore, the soluble EPS, LB-EPS, and TBEPS were, in turn, more difficult to be extracted by heating and centrifugal forces (Li et al., 2012). This result was consistent with particle size analysis, the sludge flocs were compressed and became smaller and more compact under chemical conditioning. Additionally, it was noted that the total EPS concentration of sludge floc reduced from $30.1 \mathrm{mg} / \mathrm{g}$ DS to $6.5,17.6$ and $18.1 \mathrm{mg} / \mathrm{g}$ DS under chemical conditioning with $\mathrm{FeCl}_{3}, \mathrm{PACl}$ and $\mathrm{HPAC}$ at the dosage of $10 \%$ (g/g DS) respectively. This observation reflected that the binding capacity of $\mathrm{Fe}^{3+}$ with EPS was much stronger than that of PACl and HPAC, which was in agreement with the result that sludge flocs conditioned with $\mathrm{FeCl}_{3}$ were smaller but more rigid.

3.2.2.2. Effect of chemical conditioning on soluble EPS with different MWs. The organic matters can be mainly two fractions: macromolecular fraction (>5000 Da) - mainly consisting of carbohydrates and proteins, low molecular fraction ( $<5000 \mathrm{Da}$ ) - consisting of humic substances and building blocks (Lyko et al., 2008). The coagulants conditioning had significant impacts on the molecular weight composition of soluble EPS in sludge bulk, and it was associated with high MW organic matters (see in Fig. S5 of SI). The comparison for HPSEC profile of the raw sludge filtrate with that of the conditioned indicated that the larger organic matters (MW > $2000 \mathrm{Da}$ ) were easier to be removed by coagulation. And $\mathrm{FeCl}_{3}$ showed stronger removing ability for biopolymers than PACl and HPAC. It was reported that high molecular weight biopolymers played a major role in low pressure membrane fouling while low MW compounds have minor impact (Lyko et al., 2008). Again, sludge dewaterability of activated sludge was also found to be significantly influenced by dissolved macromolecular compounds, because high strength biopolymers could block the filter medium, thereby increasing filtration resistance of sludge dewatering. This revealed that removal of high MW biopolymers also contributed to the improvement of sludge dewaterability.

\subsubsection{Correlation analysis between sludge dewatering performance and physicochemical properties of sludge system}

As shown in Fig. 5, strong correlations were found between concentration of soluble EPS, $\left(R^{2}>0.9, p<0.01\right)$, LB-EPS $\left(R^{2}>0.8\right.$, $p<0.03)$ and TB-EPS $\left(R^{2}>0.9, p<0.01\right)$ under chemical conditioning, while no significant correlations of SRF and $\mathrm{KV}, D_{\mathrm{F}}$, floc size were observed. Therefore, it is possible to evaluate efficiency of sludge conditioning with inorganic coagulants by simply measuring TOC of sludge bulk instead of SRF. These results revealed that interaction of inorganic coagulants and EPS was the major mechanism for improvement of sludge dewatering performance. In other words, the EPS structure was compressed by the addition of chemical conditioners, resulting in reduction of water retention property of EPS.

3.3. Model of change in physicochemical properties of sludge floc under chemical conditioning

It can be seen that raw sludge flocs were irregular (Fig. 6). In inorganic coagulants treatment, the floc size grew rapidly and formed visible floc within $1 \mathrm{~min}$. This is because hydrolysis products of metal salts might neutralize the surface charge of the 

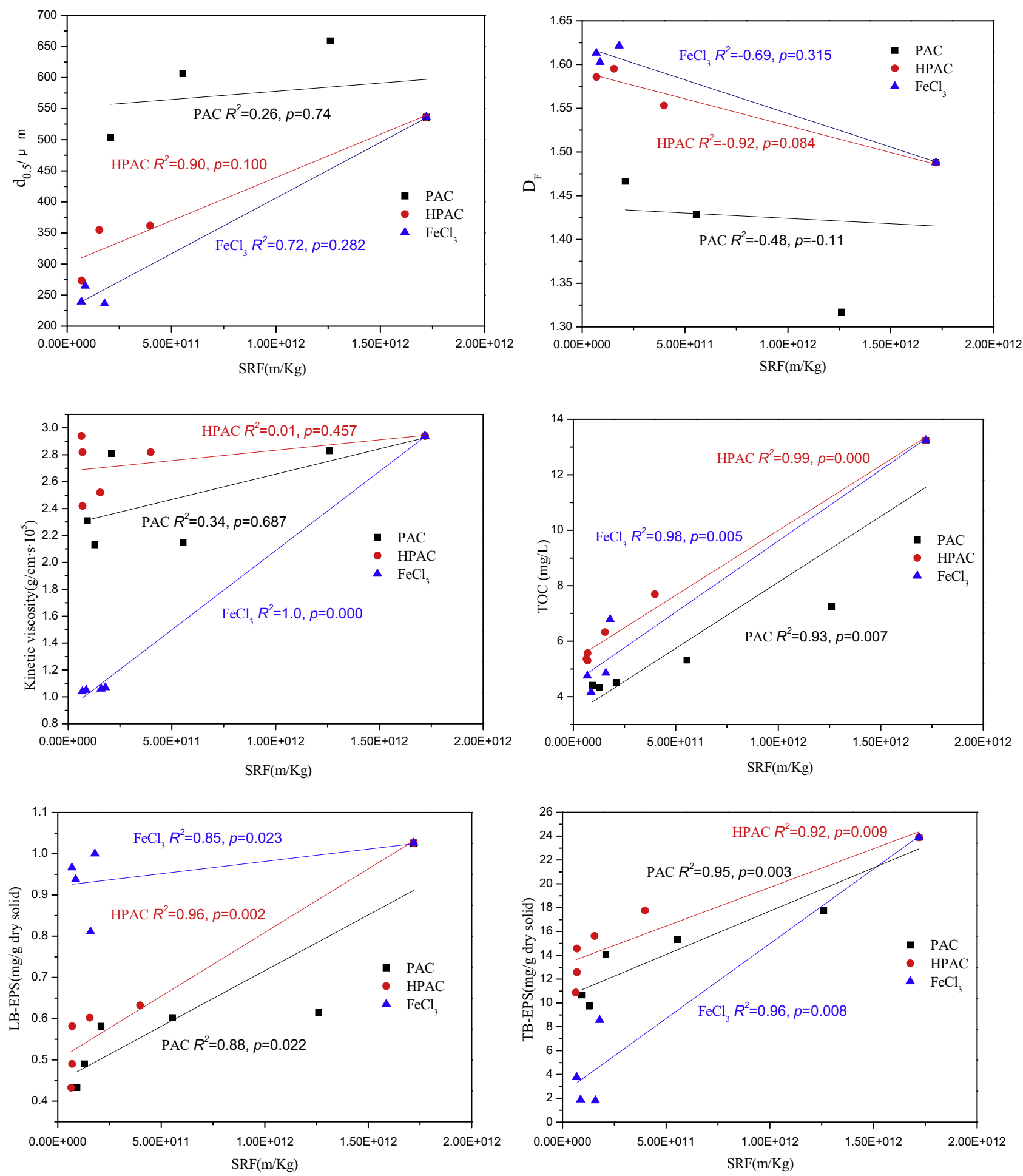

Fig. 5. Pearson correlation between SRF and physicochemical characteristics.

sludge particles and the suspension was destabilized. Then sludge floc size reduced and more compact floc were formed during the course of double electric layers. Meanwhile, water trapped in EPS released into sludge bulk solution. As a result, the particle size increased and flocs were more compact after chemical conditioning with inorganic coagulants.

Additionally, the properties of EPS located in different layers of sludge floc were also changed with chemical conditioning. Since hydrolysis products of iron and aluminum salts possessed a high binding affinity with high MW biopolymers in the bulk, LB-EPS, and TB-EPS, the EPS section was compressed due to charge neutralization and adsorption. This situation contributed to the observed trend that biopolymers located in EPS section were inclined to concentrate in the core of the sludge particle, making the flocs more rigid and compact ( $\mathrm{Li}$ et al., 2012). As mentioned above, the strength of sludge flocs was enhanced by conditioned with inorganic coagulants, revealing that chemical conditioning with inorganic coagulant was fit for high pressure dewatering process. 


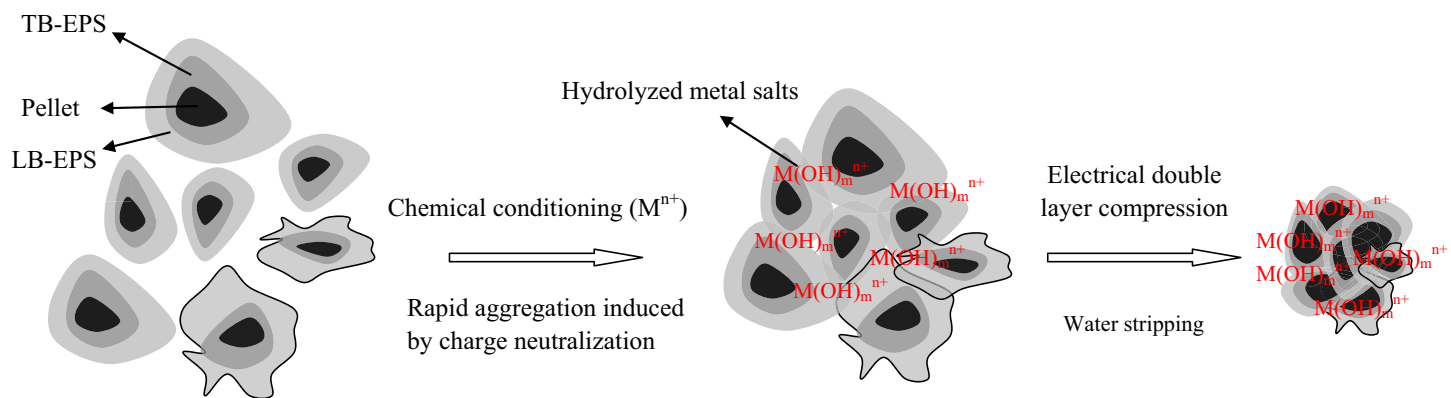

Fig. 6. Change of physicochemical structure of sludge floc under chemical conditioning.

\section{Conclusion}

Sludge dewaterability was significantly enhanced after chemical conditioning with inorganic coagulants. The conditioning process included rapid aggregation of sludge particles induced by charge neutralization and floc densification caused by double electric layer compression. Both particle size and $D_{\mathrm{F}}$ were increased under chemical conditioning, indicating that bigger and more rigid floc formed. Since the affinity of $\mathrm{Fe}^{3+}$ with EPS was much stronger, the sludge floc obtained from $\mathrm{FeCl}_{3}$ conditioning was smaller but denser than that of PACl and HPAC. Additionally, SRF correlated well with the change in concentration of soluble EPS, LB-EPS and TB-EPS, but not with $\mathrm{KV}, D_{\mathrm{F}}$, floc size.

\section{Acknowledgement}

This study was financially supported by the State Water Project for Integrated Water Supply Sludge Quality and Depth of Dewatering Technology (2012ZX07408001-05).

\section{Appendix A. Supplementary data}

Supplementary data associated with this article can be found, in the online version, at http://dx.doi.org/10.1016/j.biortech.2013.06. 126.

\section{References}

Biggs, C., Ford, A., Lant, P., 2001. Activated sludge flocculation: direct determination of the effect of calcium ions. Water Sci. Technol. 43, 75-82.

Bruus, J.H., Nielsen, P.H., Keiding, K., 1992. On the stability of activated sludge flocs with implications to dewatering. Water Res. 26, 1597-1604.

Christensen, J.R., Sørensen, P.B., Christensen, G.L., Hansen, J.A., 1993. Mechanisms for overdosing in sludge conditioning. J. Environ. Eng. 119, 159-171.

Dentel, S.K., Abu-Orf, M.M., Walker, C.A., 2000. Optimization of slurry flocculation and dewatering based on electrokinetic and rheological phenomena. Chem. Eng. J. 80, 65-72.

Eriksson, L., Alm, B., 1993. Characterization of activated sludge and conditioning with cationic polyelectrolytes. Water Sci. Technol. 28, 203-212.

Higgins, M.J., Novak, J.T., 1997. Dewatering and settling of activated sludge: the case for using cation analysis. Water Environ. Res. 69, 225-232.

Hung, W., Chang, I., Lin, W., Lee, D., 1996. Unidirectional freezing of waste-activated sludges: effects of freezing speed. Environ. Sci. Technol. 30, 2391-2396.

Jin, B., Wilén, B.-M., Lant, P., 2004. Impacts of morphological, physical and chemical properties of sludge flocs on dewaterability of activated sludge. Chem. Eng. J. 98, $115-126$.

Li, H., Wen, Y., Cao, A., Huang, J., Zhou, Q., Somasundaran, P., 2012. The influence of additives $\left(\mathrm{Ca}^{2+}, \mathrm{Al}^{3+}\right.$, and $\left.\mathrm{Fe}^{3+}\right)$ on the interaction energy and loosely bound extracellular polymeric substances (EPS) of activated sludge and their flocculation mechanisms. Bioresour. Technol. 114, 188-194.

Li, X., Yang, S., 2007. Influence of loosely bound extracellular polymeric substances (EPS) on the flocculation, sedimentation and dewaterability of activated sludge. Water Res. 41, 1022-1030.

Liyun Ge, H.W., Ma, Luming., 2006. The optimization of extracellular polymer physical extraction process. Environ. Chem. 25, 22-725 (in Chinese).

Lyko, S., Wintgens, T., Al-Halbouni, D., Baumgarten, S., Tacke, D., Drensla, K., Janot, A., Dott, W., Pinnekamp, J., Melin, T., 2008. Long-term monitoring of a full-scale municipal membrane bioreactor-characterisation of foulants and operational performance. J. Membr. Sci. 317, 78-87.

Mandelbrot, B., 1982. The Fractal Geometry of Nature. Freeman, San Francisco.

Matsui, Y., Matsushita, T., Sakuma, S., Gojo, T., Mamiya, T., Suzuoki, H., Inoue, T. 2003. Virus inactivation in aluminum and polyaluminum coagulation. Environ. Sci. Technol. 37, 5175-5180.

Mikkelsen, L.H., Keiding, K., 2002. Physico-chemical characteristics of full scale sewage sludges with implications to dewatering. Water Res. 36, 2451-2462.

Poxon, T.L., Darby, J.L., 1997. Extracellular polyanions in digested sludge: measurement and relationship to sludge dewaterability. Water Res. 31, 749758.

Qi, Y., Thapa, K.B., Hoadley, A.F., 2011. Application of filtration aids for improving sludge dewatering properties-a review. Chem. Eng. J. 171, 373-384.

Ramesh, A., Lee, D.-J., Hong, S., 2006. Soluble microbial products (SMP) and soluble extracellular polymeric substances (EPS) from wastewater sludge. Appl. Microbiol. Biotechnol. 73, 219-225.

Sheng, G.-P., Yu, H.-Q., 2006. Characterization of extracellular polymeric substances of aerobic and anaerobic sludge using three-dimensional excitation and emission matrix fluorescence spectroscopy. Water Res. 40, 1233-1239.

Simon, S., Païro, B., Villain, M., D’Abzac, P., Hullebusch, E.V., Lens, P., Guibaud, G., 2009. Evaluation of size exclusion chromatography (SEC) for the characterization of extracellular polymeric substances (EPS) in anaerobic granular sludges. Bioresour. Technol. 100, 6258-6268.

Slatter, P., 1997. The rheological characterisation of sludges. Water Sci. Technol. 36, $9-18$.

Steiner, A., McLaren, D., Forster, C., 1976. The nature of activated sludge flocs. Water Res. 10, 25-30.

Wang, D., Xing, L., Xie, J., Chow, C.W., Xu, Z., Zhao, Y., Drikas, M., 2010. Application of advanced characterization techniques to assess DOM treatability of micropolluted and un-polluted drinking source waters in China. Chemosphere 81, 39-45.

Wen, H., Liu, C., Lee, D., 1997. Size and density of flocculated sludge flocs. J. Environ. Sci. Health, Part A 32, 1125-1137.

Wu, X., Wang, D., Ge, X., Tang, H., 2008. Coagulation of silica microspheres with hydrolyzed $\mathrm{Al}(\mathrm{III})$-significance of $\mathrm{Al}_{13}$ and $\mathrm{Al}_{13}$ aggregates. Colloids Surf. A 330, 72-79.

Yang, S.-F., Li, X.-Y., 2009. Influences of extracellular polymeric substances (EPS) on the characteristics of activated sludge under non-steady-state conditions. Process Biochem. 44, 91-96.

Yu, G.-H., He, P.-J., Shao, L.-M., He, P.-P., 2008. Stratification structure of sludge flocs with implications to dewaterability. Environ. Sci. Technol. 42, 7944-7949.

Zhai, L.-F., Sun, M., Song, W., Wang, G., 2012. An integrated approach to optimize the conditioning chemicals for enhanced sludge conditioning in a pilot-scale sludge dewatering process. Bioresour. Technol. 121, 161-168.

Zhao, Y., 2002. Enhancement of alum sludge dewatering capacity by using gypsum as skeleton builder. Colloids Surf. A 211, 205-212. 